\title{
MULTIFREQUENCY OBSERVATIONS OF BL LACERTAE ${ }^{1}$
}

\author{
Joel N. Bregman, ${ }^{2}$ A. E. Gl.assgold, and P. J. Huggins \\ New York University; and the National Radio Astronomy Observatory \\ G. Neugebauer, B. T. Solfer, K. Matthews, and J. H. Elias \\ Palomar Observatory, California Institute of Technology \\ J. R. Webb, J. T. Pollock, R. J. Leacock, and A. G. Smith \\ Rosemary Hill Observatory, University of Florida \\ H. D. Aller, M. F. Aller, and P. A. Hughes \\ University of Michigan Radio Astronomy Observatory \\ D. Maccagni, B. Garilli, AND P. GiommI \\ CNR and ESTEC \\ J. S. Miller AND S. STEPhenS \\ Lick Observatory \\ T. J. BAloneK, W. A. Dent, AND W. Kinsel \\ University of Massachusetts and Colgate University \\ W. Z. WISNIEWSKI \\ Steward Observatory, University of Arizona \\ P. M. Williams aND P. W. J. L. Brand \\ United Kingdom Infrared Telescope Unit, Royal Observatory Edinburgh; and University of Edinburgh \\ AND \\ W. H.-M. KU \\ Columbia Astrophysics Laboratory, Columbia University \\ Received 1989 May 30; accepted 1989 September 28
}

\begin{abstract}
We present 20 years of optical, infrared, and radio monitoring data for BL Lac as well as four simultaneous multifrequency spectra covering the $10^{9}-10^{18} \mathrm{~Hz}$ range. Although there is no time delay between the optical and infrared variability, the high-frequency radio variations precede lower frequency variations, but only by weeks. The optical variability precedes the radio variability by a few years. The structure function for the radio variations is nearly that of shot noise for time scales less than 600 days, in contrast to the optical variation, which is similar to flicker noise. These results indicate that, although there are fundamental differences between the optical and radio emitting regions, they are related, possibly by the propagation of shocks between regions.

The multifrequency spectra show that the power per logarithmic bandwidth has a well-defined peak in the near-infrared and a sharp cutoff in the optical-ultraviolet region. This cutoff is like those seen in a few other blazars and is attributed to synchrotron losses that prevent particle acceleration from exceeding a critical energy. The X-ray continuum is not smoothly connected to the optical-ultraviolet emission and has a flatter slope, similar to that of the infrared-millimeter region. In addition, the X-ray emission varied in the same sense as the infrared-millimeter emission but opposite that of the optical-ultraviolet emission. These X-ray properties are those expected from the synchrotron-self-Compton process. The best model suggests that the plasma radiating at $\sim 10^{11.5} \mathrm{~Hz}$ has a size of $\sim 10^{-2.5} \mathrm{pc}$, a Doppler parameter of $\delta=2-3$, and a magnetic field of $B=2-40 \mathrm{G}$.

Subject headings: BL Lacertae objects - infrared: sources - radiation mechanisms - radio sources: galaxies
\end{abstract}

\section{INTRODUCTION}

The nonthermal continua of active galactic nuclei (AGNs) are most prominent in optically violent variable quasars and BL Lacertae objects, collectively referred to as blazars. These sources are polarized and variable, with many of them bright

\footnotetext{
${ }^{1}$ In view of the large number of collaborators that are required for multifrequency programs, we list the authors by research groups, but emphasize that each group has made important contributions to the data and analysis of this study.

${ }^{2}$ Work also carried out at the National Radio Astronomy Observatory, which is operated by Associated Universities, Inc., under contract with the National Science Foundation.
}

enough for study in all wavebands. In our previous investigations, we measured the continuous spectrum of several of these objects, each distinguished by some particular property such as superluminal motion, flaring, or unusual X-ray brightness $(1413+135$, Bregman et al. 1981; I Zw 187, Bregman et al. $1982 ; 1156+295$, Glassgold et al. 1983; $0725+178$, Bregman et al. 1984; 3C 345, Bregman et al. 1986; and 3C 446, Bregman et al. 1988). Related studies have been undertaken by several other groups that included some of the present authors (e.g., Kondo et al. 1981; Worrall et al. 1982; Mufson et al. 1984; Maraschi et al. 1985; Landau et al. 1986; Makino et al. 1987). Here we investigate BL Lacertae, archetype of its class and one 
of the most interesting and important sources for studies of this kind.

BL Lac, which lies in a giant elliptical galaxy at a redshift of 0.0688 (Miller, French, and Hawley 1978), is one of the beststudied blazars at optical and radio wavelengths. Nearly all the radio flux is emitted from a region smaller than 100 mas (Stannard and McIlwrath 1982). Faint extended emission (only $29 \mathrm{mJy})$ comes from a region $48 \mathrm{kpc}$ in extent $\left(H_{0}=75 \mathrm{~km} \mathrm{~s}^{-1}\right.$ $\mathrm{Mpc}^{-1}$; used throughout). Superluminal components are seen frequently on the milliarcsecond scale, and during 1980-1984, four components emerged with apparent velocities of $3.3 \mathrm{c}$ (Mutel and Phillips 1987). Both the core and the knots are sometimes unresolved, even with resolution better than 0.5 mas (Baath et al. 1981; Wardle and Roberts 1988). The emission from the superluminal components is polarized, and the angle of the derotated polarization vector $\left(5^{\circ}-25^{\circ}\right)$ is the same as the position angle of the VLBI structure $\left(8^{\circ}-18^{\circ}\right.$; Hughes, Aller, and Aller 1985, 1988; Phillips and Mutel 1988; Mutel and Phillips 1988; Wardle and Roberts 1988). This has led to the suggestion that a weak shock propagates along a jet, locally compressing the field nearly perpendicular to the jet axis and yielding significant polarized emission in the postshock region (Marscher and Gear 1985; Hughes, Aller, and Aller $1989 a, b)$. To accommodate the simple relativistic aberration model for superluminal motion, a model is used in which the shocked downstream fluid has a Lorentz factor (observer's frame) of $\gamma=4.0$, the shock propagates at $\gamma=2.5$, and the jet axis lies about $38^{\circ}$ from the line of sight (Hughes, Aller, and Aller 1989b). From the data presented here, shocks and bulk relativistic motion are also inferred.

The optical and infrared emission of BL Lac is variable and polarized, with some correlation indicated between radio and optical polarizations (Sitko, Schmidt, and Stein 1985). The distribution of optical polarization angles has a peak near $20^{\circ}$ and a broad width, which becomes more narrow as the brightness of BL Lac decreases (Moore et al. 1982; Brindle et al. 1985; Sitko, Schmidt, and Stein 1985; Smith 1986; Hagen-Thorn and Yacovleva 1987; Moore, Schmidt, and West 1987). Changes in the polarized flux of $1^{\circ} \mathrm{hr}^{-1}$ and the polarization angle of $5^{\circ}$ $\mathrm{hr}^{-1}$ have led to the suggestion that several small $(\geq 1 \mathrm{lt}-\mathrm{hr})$, variable, and highly polarized components produce the net observed emission (Moore, Schmidt, and West 1987; see also Bjornsson 1986). The variability behavior suggests a total size of the optical emitting region of approximately a few light days.

In this work, we present both monitoring data and multifrequency spectra for BL Lac. The monitoring data at optical, infrared, millimeter, and centimeter wavelengths cover a 20 year period and permit a detailed search for correlated variability. In addition, we determine the character of the variability by using structure functions ( $\S$ II). The multifrequency spectra were obtained during outbursts as well as during more normal periods. These spectra include ground-based observations as well as X-ray data from the Einstein and EXOSAT satellites, ultraviolet data from the $I U E$, and infrared data from IRAS (§ III). These multifrequency spectra permit us to investigate the origin of the X-ray emission and to determine the physical parameters of the emitting regions (§ IV). As a result, a picture of the emitting region that extends over a wide range of size scales is realized.

\section{MONITORING DATA}

Because of its distinction as the object that defines its class, BL Lac has been extensively studied for a period of about 20 years in several wavebands. Here we present the most complete set of optical, near-infrared, and radio monitoring data available for BL Lac, and we discuss the nature of its variability by employing structure functions and correlation analysis. Corrections for galactic absorption have not been applied to any of the optical monitoring data, some of which has previously been published elsewhere (Pica et al. 1980; Pollock 1983; Webb et al. 1988; Aller et al. 1985; Hagen-Thorn, Marchenko, and Yacovleva 1985).

\section{a) Methodology}

Variability of data can be described in a statistical manner by the use of structure functions (e.g., Simonetti, Cordes, and Heeschen 1986). As used here, the structure function provides a measure of the mean difference in the flux densities as a function of the separation in the sampling interval. Formally, it is defined as

$$
S F(\Delta t)=\left\langle[F(t)-F(t+\Delta t)]^{2}\right\rangle .
$$

A power spectrum analysis gives information similar to a structure function analysis, but the latter method has advantages when examining nonperiodic data. There is a simple correspondence between power laws in a Fourier analysis, fractal analysis, or structure function analysis. If $S F \propto t^{a}$, then the fractal function would be proportional to $t^{a / 2}$ and the Fourier power spectrum $P \propto f^{-(a+1)}$, where $f$ is frequency.

A second method of analysis used here is one in which we search for a correlation in the variability at two different wavelengths. A simple approach is taken (Bregman et al. 1988) in which the two data sets are scaled and normalized such that the total range is between -0.5 and 0.5 with a mean of 0 . One data set is shifted in time $(\Delta t)$ with respect to the other, and the mean variance is calculated. This is formally expressed as:

$$
M V=\frac{1}{n} \sum_{1}^{n}[F(t+\Delta t)-G(t)]^{2},
$$

where $F$ and $G$ are the two data sets. In practice, an observed value of $G(t)$ may not have been made at a particular shifted time $t+\Delta t$. In these cases, interpolated values are used, where the interpolation was carried out for the better sampled and more slowly varying of the two data sets.

\section{b) Radio Data}

The radio data were obtained at the University of Michigan Radio Observatory (Aller et al. 1985), at Haystack Observatory, at the NRAO (Balonek 1982; Johnston et al. 1984), and with the Aerospace $4.6 \mathrm{~m}$ millimeter wave telescope (Epstein et al. 1982). Figure 1 shows that the behavior of the flux densities in the different radio bands is quite similar, and this leads to similar structure functions. The most uniform and accurate data over the longest time scale are at $8 \mathrm{GHz}$, for which the structure function has a slope $a=0.8$ for 50 days $<\Delta t<600$ days and flattens to nearly zero slope for longer time scales (Fig. 2). The results for $4.8 \mathrm{GHz}$ and $15 \mathrm{GHz}$ are not significantly different $(a=0.8-1.0)$. Using a shorter time base, Johnston et al. 1984) and Fiedler et al. (1987) analyzed 2.7 and 8.1 $\mathrm{GHz}$ data closely spaced in time and found that $a=0.9$ for 2 days $<\Delta t<100$ days (Johnston et al. 1984) and $a=1.4,1.3$ (for 2.7 and $8.1 \mathrm{GHz}$, respectively) for 10 days $<\Delta t<200$ days (Fielder et al. 1987). These results indicate that the structure function has a similar slope for $\Delta t=2-600$ days and that this slope is nearly that of shot noise $(a=1)$. It also implies that there is no unique minimum time scale. The shortest time scale 

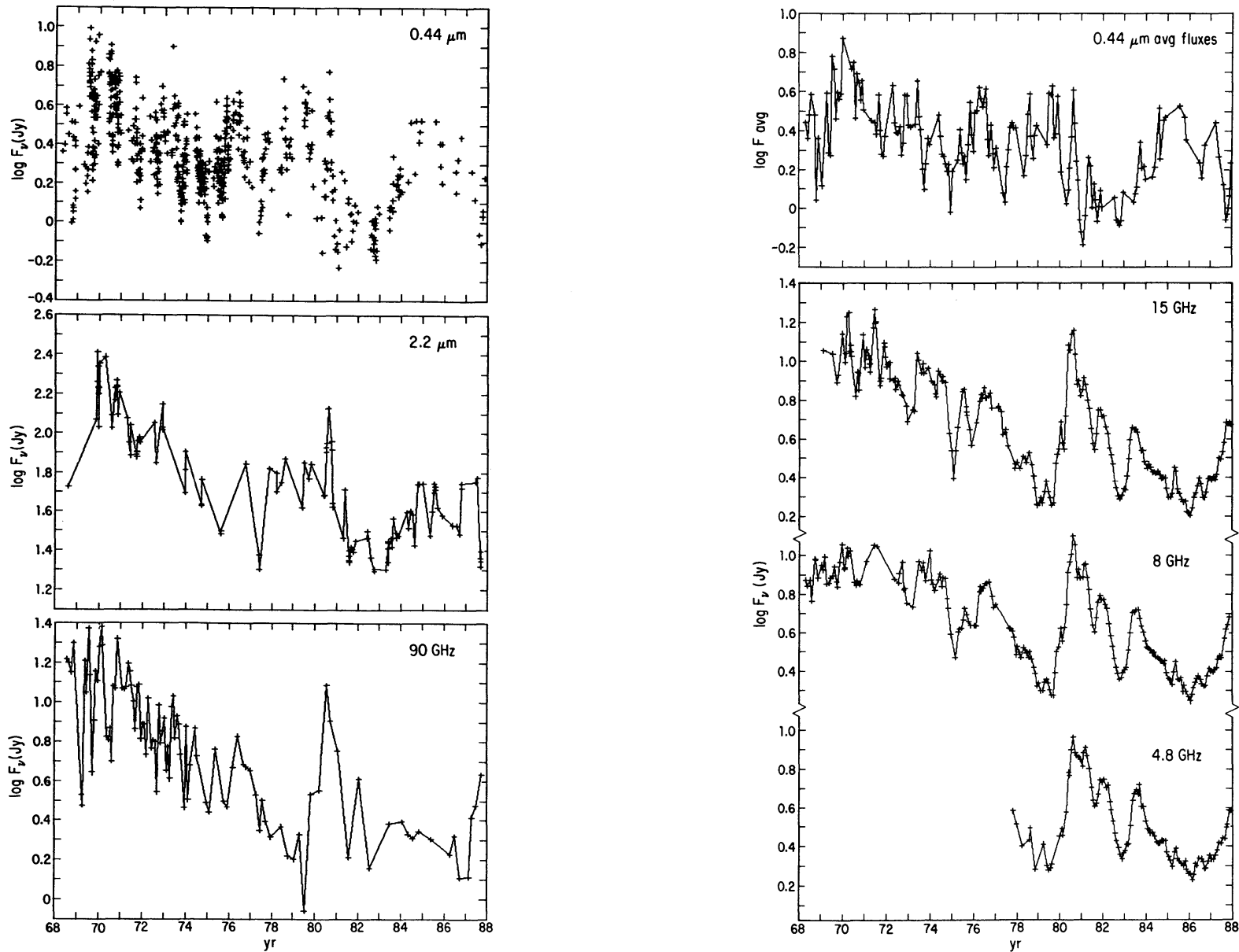

FIG. $1 b$

FIG. 1. (a) Monitoring data at $0.44 \mu \mathrm{m}, 2.2 \mu \mathrm{m}$, and $90 \mathrm{GHz}$ during $1968-1988$ for BL Lac. (b) Monitoring data during $1968-1988$ for BL Lac. The 0.44 $\mu \mathrm{m}$ data is averaged into 3 month bins, while monthly averages are given for the $4,8,8$, and $15 \mathrm{GHz}$ measurements.

$(d t / d \log F)$ yet seen is 20 days (determined by observations where $\Delta t=2$ days). If this time scale is a measure of the size of the radiating region, an enormous brightness temperature is implied. This dilemma is often resolved by appealing to Doppler boosting, by a special geometry, or both. The flattening of the structure function at $\Delta t \simeq 600$ days $(a=0.0-0.4)$ shows that the most common variability occurs with a time scale less than $2 \mathrm{yr}$.

Correlation analyses of the radio observations show that the data at any two frequencies are well correlated with little time delay (Fig. 3). The $90 \mathrm{GHz}$ data seem to precede the $15 \mathrm{GHz}$ data by about three weeks, the $15 \mathrm{GHz}$ data precede the $8 \mathrm{GHz}$ data by about two weeks, and the $8 \mathrm{GHz}$ data precede the 5 $\mathrm{GHz}$ data by about two weeks (delays less than 30 days are difficult to measure; Fielder et al. 1987 find the $8.1 \mathrm{GHz}$ variation precede those at $2.7 \mathrm{GHz}$ by 31 days). The small time delay in flux variation (noted previously by Johnston et al. 1984; Aller, Aller, and Hughes 1985) suggests that the radio region is remarkably transparent most of the time. In particular, the data rule out the expanding source model in which the opacity decreases with time, leading to outbursts at later times for lower frequency radiation. However, the observations are well-fitted by a propagating shock model involving in situ particle acceleration (e.g., Hughes, Aller, and Aller 1989a, b).

\section{c) Optical-Infrared Data}

Most of the optical data were obtained at the Rosemary Hill Observatory by Smith and collaborators using photographic techniques (Webb et al. 1988). Additional optical monitoring data is available in the literature for BL Lac (Pollock 1983, and references therein), and this has been included in the analysis. To check that the results are not influenced by the inhomogeneous nature of this data set, analysis was also carried out using only the Rosemary Hill data and using weighted monthly averages of the complete data set. Most of the infrared data were obtained at Palomar observatory by Neugebauer and collaborators, providing a uniform data set with errors of typically $5 \%$ or less. However, beam size effects can be important when BL Lac is faint. The observed infrared flux can differ by $10 \%-15 \%$ between measurements made with $5^{\prime \prime}$ and $10^{\prime \prime}$ diameter apertures. The characteristics of the observing system, the calibration standards, and the stability of the system are described in Neugebauer et al. (1989).

The infrared and optical data have a greater amount of rapid flicker than the radio data (Fig. 1), and this is verified by a difference in the structure functions (Fig. 2); rapid infrared polarization variations have been discussed by Impey et al. (1984). For the optical and infrared data sets, the structure 


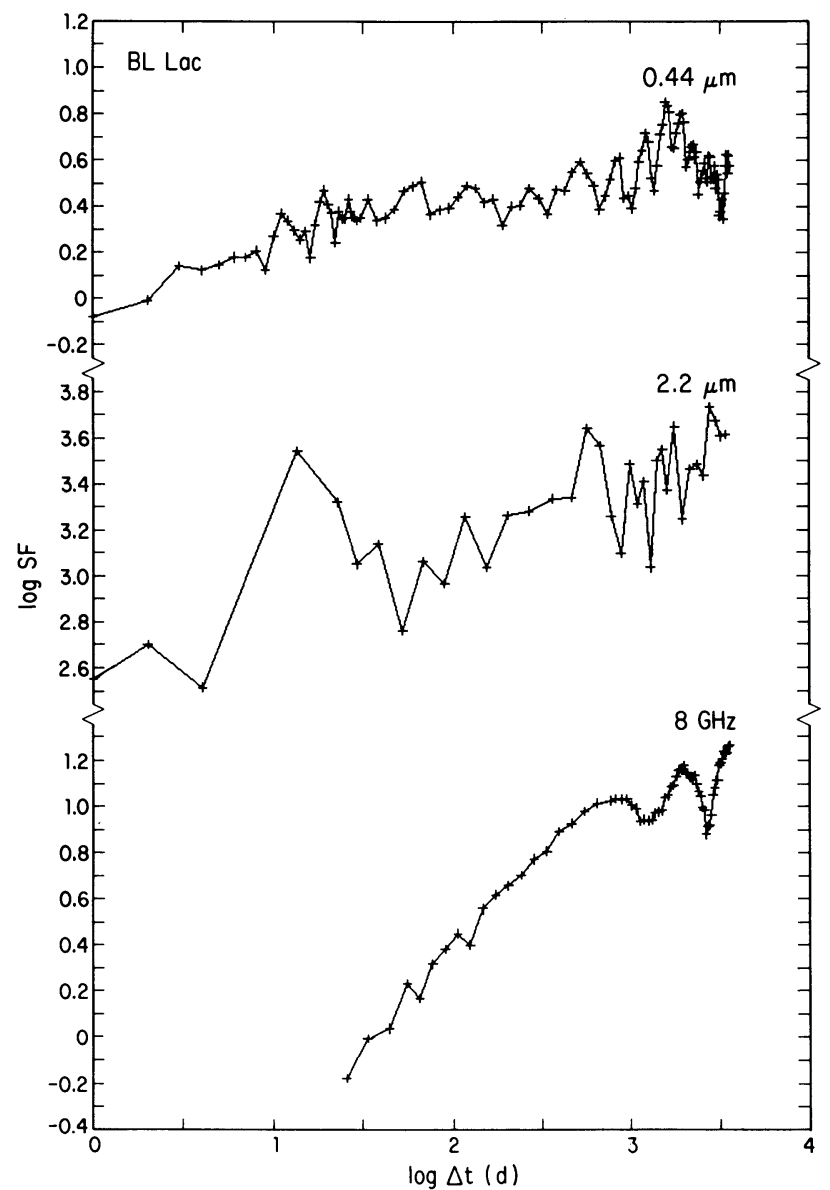

Fig. 2. - The log of the structure function is plotted against the log of the time interval for optical, infrared, and radio frequencies. The large scatter at 2.2 $\mu \mathrm{m}$ is due to the paucity of data; the feature at 10 days may not be statistically significant. Notice the similarity between the optical and infrared structure functions and their difference with that at $8 \mathrm{GHz}$.

function is fairly flat for $\Delta t>100$ days with a slope $a=0.0$ 0.3 , while for $\Delta t<100$ days, $a=0.2-0.4$ (Fig. 2). This demonstrates that there exists considerably more power at short time scales than in the radio data. The amount of power in shortterm variations can change with time, and Smith, Leacock, and Webb (1987) have noted that since 1980, flickering is less prominent (although still with much more power than radio flickering).

Cross-correlation studies were performed to determine the connection between optical and infrared variability. A strong correlation is found between the 0.44 and $2.2 \mu \mathrm{m}$ fluxes with no measurable delay (Fig. 3); formally, the $2.2 \mu$ m fluxes lag behind with $\Delta t=1.5 \pm 2.0$ days.

The multicolor infrared observations permit a study of the spectral variation. Between 1976 and 1988, the flux density was measured at $1.25,1.65$, and $2.2 \mu \mathrm{m}$ sequentially on the same night on 68 different occasions. In general, the $1.25-2.2 \mu \mathrm{m}$ slope lies in the range -1.0 to -1.3 (Fig. 4), and most of the dispersion is probably due to the uncertainty in the slope (typically 0.14). However, during the outburst in 1980, when BL Lac achieved its greatest infrared brightness in the 19761988 period (Fig. 1), the spectrum was noticeably steeper. Steepening also occurred in the 2.2-10.1 $\mu \mathrm{m}$ range, with $\alpha$ decreasing by 0.15 . Thus, the entire infrared spectrum softened during the outburst.

\section{d) The Optical-Radio Connection}

For this correlation study, the $0.44 \mu \mathrm{m}$ flux densities were averaged into 1 month intervals in order to avoid the problem that sampling was more frequent during the first 9 years; monthly averages of the radio data were also used. Correlation analyses of the optical-infrared data with the radio data indicate that the variation of the radio fluxes lags behind that of the optical-infrared fluxes by several years (Fig. 3). There is a broad but significant minimum in the mean variance between $1.0-4.5 \mathrm{yr}$ for the correlation of both the optical and infrared fluxes with the $8 \mathrm{GHz}$ data. The minimum is not as broad when the optical data is compared to the $15 \mathrm{GHz}$ fluxes. Only one well-defined minimum is seen near $4.0 \mathrm{yr}$.

Although the structure functions for radio and optical data are significantly different for time scales less than a few hundred days, they are more similar for longer time scales (600 days $<\Delta t<3500$ days). The comparison is hampered because the data extend to only about 7000 days, so a few outbursts with spacings of years add features to the structure functions. When combined with the correlation analyses, we conclude that the long time scale variations at both the optical-infrared and radio regions are caused by the same outbursts.

\section{MULTIFREQUENCY SPECTRA}

Multifrequency spectra were obtained on four dates: 1980 June, 1983 June, 1983 December, and 1984 May. Radio, millimeter, infrared, optical, and ultraviolet data were obtained on each occasion, far infrared/submillimeter data were obtained for two spectra (1983 June and 1983 December), while X-ray measurements were obtained during 1980 June and 1983 December (Table 1, Fig. 5). Because of the large number of observatories and instruments used, the details of each observation are not given when the procedures are standard and have been described elsewhere.

The reddening to BL Lac has been determined by several approaches. Du Puy et al. (1969) examined the reddening of halo $\mathrm{K}$ giants near the line of sight to BL Lac and obtained $E(B-V)=0.31$, while Thuan, Oke, and Gunn (1975) estimated $0.28<E(B-V)<0.40$. We also estimated the reddening from the $\mathrm{H}$ I column density in that direction (Burstein and Heiles 1978 ) to obtain $E(B-V)=0.26 \pm 0.06$. For the purposes of this work, we adopt the value $E(B-V)=0.31$ when correcting the infrared, optical, and ultraviolet observations and values of $A(\lambda) / E(B-V)$ given by Seaton (1980). To correct the X-ray observations for absorption, $\log N_{\mathrm{H}}=22.1$ is used, which is the value determined directly from a spectral fit to the pulse-height data of the Einstein Observatory IPC observation. This is greater than the galactic value determined from $\mathrm{H}$ I maps (log $N_{\mathrm{H}}=21.3$; Burstein and Heiles 1978) and suggests that additional absorbing material may lie in the host galaxy.

\section{a) General Features of a Single Spectrum}

The multifrequency spectra, displayed as power per logarithmic bandwidth $\left(v F_{v}\right)$ versus $\log v$, are shown in Figure 5. The striking peak near $\log v=14.3$ is caused by a remarkable steepening of the optical-ultraviolet continuum, which is nearly an exponential function of frequency. This is seen more clearly in Figure 6, which shows the mean spectral slope of all multifrequency spectra. If the optical-ultraviolet spectrum is extrapolated to higher frequency, no observable X-ray emis- 

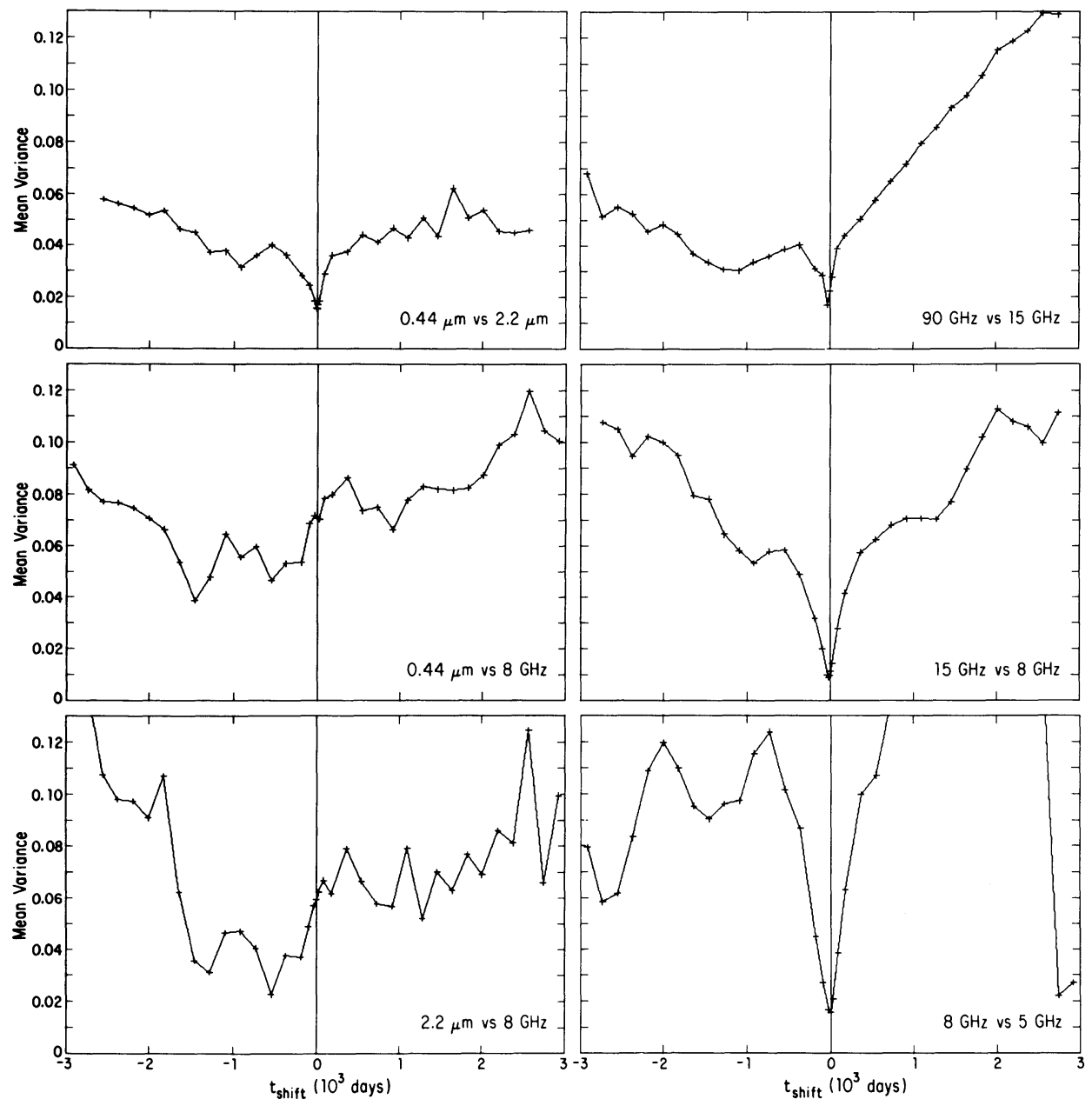

Fig. 3.-The mean variance (MV) of different pairs of fluxes is shown as a function of time shift. A minimum in $\mathrm{MV}$ at negative $\Delta t$ indicates that a correlation exists, with the first listed quantity preceding the second by that amount. Most of the figures have values for MV calculated at $\Delta t=0, \pm 30$, and \pm 90 days, and then at half-year intervals beginning with $0.5 \mathrm{yr}$.

sion is expected. X-ray emission was, however, clearly detected on two occasions, indicating that the $\mathrm{X}$-rays are not an extension of the synchrotron emission in the radio-ultraviolet region (Fig. 5).

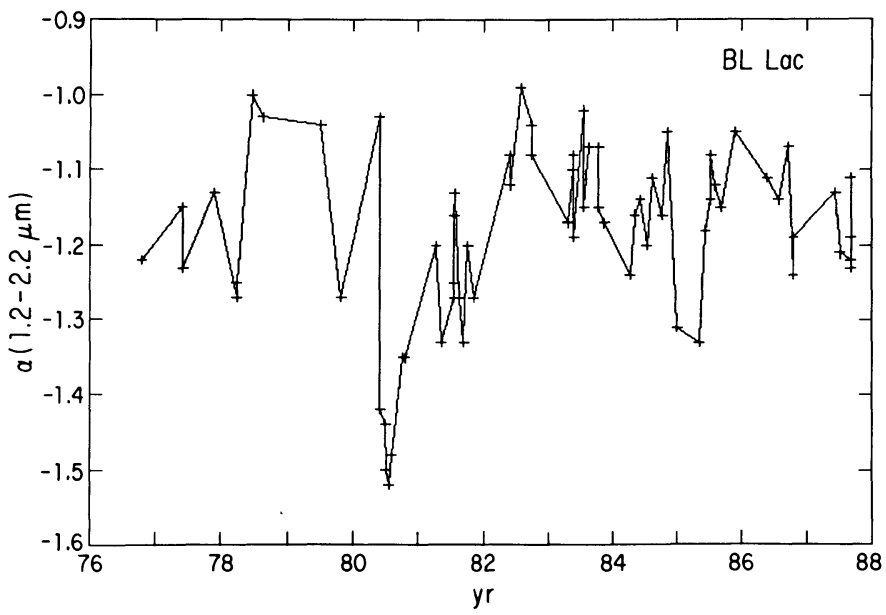

FIG. 4.-The infrared slope for BL Lacertae is determined with a typical error of 0.14 . The spectral steepening that occurred in 1980 is associated with an outburst when BL Lac became brighter than at any other time during 1976-1988.
Most of the radiated power emerges in the infrared-optical region, with only minor contributions from other wavebands. It is difficult to determine accurately the total $\mathrm{X}$-ray luminosity because the peak in the power per logarithmic bandwidth in the $10-500 \mathrm{keV}$ range is not observed. To estimate the integrated X-ray flux, we assumed that the X-ray continuum is described by a power law of slope $\alpha=-0.7$ (suggested by the data; see below) to an energy of $100 \mathrm{keV}$. Under these assumptions, the total integrated $\mathrm{X}$-ray flux is about $10 \%$ of the radioUV flux (Table 2); extending the X-ray continuum to $500 \mathrm{keV}$ (the electron pair production energy) increases the integrated $\mathrm{X}$-ray flux to $16 \%$ of the radio-ultraviolet flux.

\section{b) Specific Spectra}

1980 June.-The source was undergoing a radio outburst at this time, although there was no simultaneous optical outburst. As is frequently seen during the brightening phase of radio outbursts, the radio spectrum is inverted in the $\mathrm{cm}$ region and flattens in the $\mathrm{mm}$ region.

The X-ray spectrum is composed of measurements from two instruments, the IPC and the MPC of the Einstein Observatory (integration time of $4323 \mathrm{~s}$; sequence number 5693). The spectral fit to the IPC data $(0.1-4 \mathrm{keV})$ shows a slope of $\alpha=-2.2 \pm 1.0$, the slope determined from the MPC data (2-10 $\mathrm{keV}$ ) is $\alpha=-0.8 \pm 0.5$, and the spectrum connecting the MPC 
TABLE 1

MUlTifrequenCy Data for BL LAC

\begin{tabular}{|c|c|c|c|c|c|c|}
\hline Name & Date & Region & $\log \nu(\mathrm{Hz}$ & z) Flux & $\log \mathrm{F}_{\nu}{ }^{1}$ & $\log \sigma$ \\
\hline $\begin{array}{l}\mathrm{Ku} \\
\text { Columbia }\end{array}$ & 8 Jun 80 & $\begin{array}{rr}1 \mathrm{keV} \\
5.6 \mathrm{keV}\end{array}$ & $\begin{array}{l}17.38 \\
18.13\end{array}$ & $\begin{array}{l}1.60 \mathrm{E}-29^{2} \\
5.00 \mathrm{E}-30\end{array}$ & $\begin{array}{l}-28.80 \\
-29.30\end{array}$ & $\begin{array}{l}0.06 \\
0.12\end{array}$ \\
\hline $\begin{array}{l}\text { Bregman, Glassgold, } \\
\text { and Huggins } \\
\text { NYU and NRAO }\end{array}$ & 8 Jun 80 & $\begin{array}{l}2525^{3} \\
2850\end{array}$ & $\begin{array}{l}15.075 \\
15.022\end{array}$ & $\begin{array}{l}3.69 E-16^{4} \\
5.95 E-16\end{array}$ & $\begin{array}{l}-26.20 \\
-26.06\end{array}$ & $\begin{array}{l}0.05 \\
0.03\end{array}$ \\
\hline $\begin{array}{l}\text { Webb, Pollock, Pica, } \\
\text { Smith, and Leacock } \\
\text { Univ. Florida }\end{array}$ & 11 Jun 80 & $\begin{array}{l}3600 \\
4400 \\
5500\end{array}$ & $\begin{array}{l}14.92 \\
14.83 \\
14.74\end{array}$ & $\begin{array}{l}0.44^{5} \\
1.36 \\
2.51\end{array}$ & $\begin{array}{l}-25.75 \\
-25.36 \\
-25.22\end{array}$ & $\begin{array}{l}0.06 \\
0.06 \\
0.06\end{array}$ \\
\hline $\begin{array}{l}\text { Miller } \\
\text { Lick Obs. }\end{array}$ & 8 Jun 80 & $\begin{array}{l}4200 \\
4500 \\
5000 \\
5500 \\
6000 \\
6500 \\
7000 \\
7500\end{array}$ & $\begin{array}{l}14.85 \\
14.82 \\
14.78 \\
14.74 \\
14.70 \\
14.66 \\
14.63 \\
14.60\end{array}$ & $\begin{array}{l}0.83 \\
1.08 \\
1.66 \\
2.36 \\
3.04 \\
3.72 \\
4.68 \\
5.72\end{array}$ & $\begin{array}{l}-25.55 \\
-25.47 \\
-25.34 \\
-25.24 \\
-25.17 \\
-25.11 \\
-25.04 \\
-24.98\end{array}$ & $\begin{array}{l}0.02 \\
0.02 \\
0.02 \\
0.02 \\
0.02 \\
0.02 \\
0.02 \\
0.02\end{array}$ \\
\hline $\begin{array}{l}\text { Williams, Brand } \\
\text { UKIRT }\end{array}$ & 1 Jun 80 & $\begin{array}{l}1.25^{6} \\
1.65 \\
3.80\end{array}$ & $\begin{array}{l}14.38 \\
14.26 \\
13.90\end{array}$ & $\begin{array}{r}25.0 \\
39.1 \\
100\end{array}$ & $\begin{array}{l}-24.51 \\
-24.35 \\
-24.00\end{array}$ & $\begin{array}{l}0.02 \\
0.02 \\
0.02\end{array}$ \\
\hline $\begin{array}{l}\text { Neugebauer, Soifer } \\
\text { Palomar Obs. }\end{array}$ & 2 Jun 80 & $\begin{array}{l}1.25 \\
1.65 \\
2.2\end{array}$ & $\begin{array}{l}14.38 \\
14.26 \\
14.13\end{array}$ & $\begin{array}{l}19.7 \\
31.0 \\
46.2\end{array}$ & $\begin{array}{l}-24.61 \\
-24.45 \\
-24.30\end{array}$ & $\begin{array}{l}0.02 \\
0.02 \\
0.02\end{array}$ \\
\hline $\begin{array}{l}\text { Balonek, Dent, and } \\
\text { Barvanis } \\
\text { Univ. Mass. }\end{array}$ & $\begin{array}{l}\text { Jun } 80 \\
\text { Jun } 80\end{array}$ & $\begin{array}{l}89.6^{7} \\
31.4\end{array}$ & $\begin{array}{l}10.95 \\
10.50\end{array}$ & $\begin{array}{c}9.20^{8} \\
12.50\end{array}$ & $\begin{array}{l}-22.04 \\
-21.90\end{array}$ & $\begin{array}{l}0.03 \\
0.01\end{array}$ \\
\hline $\begin{array}{l}\text { Flett and } \\
\text { Henderson (1981) }\end{array}$ & 2 Jun 80 & 33.5 & 10.53 & 15.0 & -21.82 & 0.02 \\
\hline $\begin{array}{l}\text { Aller, Aller, } \\
\text { and Hodge } \\
\text { Univ. Mich. }\end{array}$ & 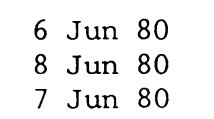 & $\begin{array}{r}14.5 \\
8.0 \\
4.8\end{array}$ & $\begin{array}{r}10.16 \\
9.90 \\
9.68\end{array}$ & $\begin{array}{r}12.9 \\
9.2 \\
6.11\end{array}$ & $\begin{array}{l}-21.889 \\
-22.036 \\
-22.214\end{array}$ & $\begin{array}{l}0.013 \\
0.014 \\
0.014\end{array}$ \\
\hline $\begin{array}{l}\text { Bregman, Glassgold, } \\
\text { and Huggins } \\
\text { NYU and NRAO }\end{array}$ & 11 Jun 83 & $\begin{array}{l}2600^{3} \\
2700 \\
2800 \\
3000 \\
3100\end{array}$ & $\begin{array}{l}15.062 \\
15.046 \\
15.030 \\
15.000 \\
14.986\end{array}$ & $\begin{array}{l}3.61 E-16^{4} \\
4.63 E-16 \\
8.08 E-16 \\
1.00 E-15 \\
9.38 E-16\end{array}$ & $\begin{array}{l}-26.26 \\
-26.16 \\
-25.92 \\
-25.84 \\
-25.85\end{array}$ & $\begin{array}{l}0.07 \\
0.07 \\
0.07 \\
0.08 \\
0.08\end{array}$ \\
\hline $\begin{array}{l}\text { Webb, Pollock, Pica, } \\
\text { Smith, and Leacock } \\
\text { Univ. Florida }\end{array}$ & $\begin{array}{l}9.4 \text { Jun } 83 \\
10.4 \text { Jun } 83\end{array}$ & $\begin{array}{l}4400 \\
3600 \\
4400 \\
5500 \\
3600 \\
4400 \\
5500\end{array}$ & $\begin{array}{l}14.83 \\
14.92 \\
14.83 \\
14.74 \\
14.92 \\
14.83 \\
14.74\end{array}$ & $\begin{array}{l}16.50^{9} \\
16.29 \\
16.57 \\
15.34 \\
16.59 \\
16.58 \\
15.26\end{array}$ & $\begin{array}{l}-25.47 \\
-25.82 \\
-25.47 \\
-25.16 \\
-25.80 \\
-25.47 \\
-25.16\end{array}$ & $\begin{array}{l}0.05 \\
0.04 \\
0.03 \\
0.05 \\
0.07 \\
0.03 \\
0.04\end{array}$ \\
\hline
\end{tabular}


TABLE 1-Continued

\begin{tabular}{|c|c|c|c|c|c|c|c|c|}
\hline Name & & Date & Region & $\log \nu(H$ & $(\mathrm{Hz})$ & Flux & $\log F_{\nu}$ & $\log \sigma$ \\
\hline Sitko et al. 1985 & 8 & 8 Jun 83 & $\begin{array}{l}3600 \\
4400 \\
5500 \\
6400 \\
7900 \\
3600 \\
4400 \\
5500 \\
6400 \\
7900\end{array}$ & $\begin{array}{l}14.92 \\
14.83 \\
14.74 \\
14.67 \\
14.58 \\
14.92 \\
14.83 \\
14.74 \\
14.67 \\
14.58\end{array}$ & & $\begin{array}{l}0.40^{5} \\
1.14 \\
2.51 \\
4.04 \\
6.71 \\
0.40 \\
1.06 \\
2.18 \\
3.69 \\
6.06\end{array}$ & $\begin{array}{l}-25.79 \\
-25.43 \\
-25.22 \\
-25.07 \\
-24.93 \\
-25.79 \\
-25.46 \\
-25.28 \\
-25.11 \\
-24.98\end{array}$ & $\begin{array}{l}0.02 \\
0.02 \\
0.02 \\
0.02 \\
0.02 \\
0.02 \\
0.02 \\
0.02 \\
0.02 \\
0.02\end{array}$ \\
\hline $\begin{array}{l}\text { Neugebauer, Soifer } \\
\text { Palomar Obs. }\end{array}$ & & $\begin{array}{l}1 \text { May } 83 \\
25 \text { May } 83\end{array}$ & $\begin{array}{c}1.25^{6} \\
1.65 \\
2.2 \\
3.7 \\
10.1\end{array}$ & $\begin{array}{l}14.38 \\
14.26 \\
14.13 \\
13.91 \\
13.47\end{array}$ & & $\begin{array}{r}12.70 \\
18.30 \\
25.30 \\
40.2 \\
97.7\end{array}$ & $\begin{array}{l}-24.80 \\
-24.68 \\
-24.56 \\
-24.40 \\
-24.01\end{array}$ & $\begin{array}{l}0.03 \\
0.02 \\
0.02 \\
0.04 \\
0.07\end{array}$ \\
\hline $\begin{array}{l}\text { Neugebauer, Miley, } \\
\text { and others } \\
\text { IRAS }\end{array}$ & & 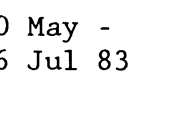 & $\begin{array}{l}12 \\
25 \\
60\end{array}$ & $\begin{array}{l}13.40 \\
13.08 \\
12.70\end{array}$ & & $\begin{array}{l}128 \\
242 \\
466\end{array}$ & $\begin{array}{l}-23.89 \\
-23.62 \\
-23.33\end{array}$ & $\begin{array}{l}0.02 \\
0.01 \\
0.01\end{array}$ \\
\hline $\begin{array}{l}\text { Dent, Kinsel, and } \\
\text { Balonek } \\
\text { Univ. Mass. }\end{array}$ & 15 & 5 Jun 83 & $83.45^{7}$ & 10.92 & & $2.42^{8}$ & -22.62 & 0.03 \\
\hline $\begin{array}{l}\text { Howard } \\
\text { NRAO }\end{array}$ & 11 & Jun 83 & 89.60 & 10.95 & & 3.40 & -22.47 & 0.05 \\
\hline $\begin{array}{l}\text { Aller, Aller, } \\
\text { and Hodge } \\
\text { Univ. Mich: }\end{array}$ & & $\begin{array}{l}3 \text { Jun } 83 \\
-23 \text { Jun } 83 \\
-24 \text { Jun } 83\end{array}$ & $\begin{array}{r}14.5 \\
8.0 \\
4.8\end{array}$ & $\begin{array}{r}10.16 \\
9.90 \\
9.68\end{array}$ & & $\begin{array}{l}4.39 \\
5.04 \\
4.72\end{array}$ & $\begin{array}{l}-22.357 \\
-22.298 \\
-22.326\end{array}$ & $\begin{array}{l}0.004 \\
0.004 \\
0.004\end{array}$ \\
\hline $\begin{array}{l}\text { Maccagni, Garilli, } \\
\text { and Giommi } \\
\text { CNR, EXOSAT }\end{array}$ & 8 & Dec 83 & $1 \mathrm{kev}$ & 17.38 & & $0 O E-30^{2}$ & -29.10 & 0.06 \\
\hline $\begin{array}{l}\text { Bregman, Glassgold, } \\
\text { and Huggins } \\
\text { NYU and NRAO }\end{array}$ & 8 & $\operatorname{Dec} 83$ & $\begin{array}{l}2650^{3} \\
2750 \\
2850 \\
2950\end{array}$ & $\begin{array}{l}15.054 \\
15.038 \\
15.022 \\
15.007\end{array}$ & $\begin{array}{l}1.7 \\
1.6 \\
1.2 \\
1.4\end{array}$ & $\begin{array}{l}75 E-15^{4} \\
67 E-15 \\
27 E-15 \\
46 E-15\end{array}$ & $\begin{array}{l}-25.57 \\
-25.60 \\
-25.73 \\
-25.66\end{array}$ & $\begin{array}{l}0.12 \\
0.06 \\
0.09 \\
0.07\end{array}$ \\
\hline $\begin{array}{l}\text { Miller and Stephens } \\
\text { Lick Obs. }\end{array}$ & 6 & Dec 83 & $\begin{array}{l}4500 \\
5000 \\
5500 \\
6000 \\
6500 \\
7000\end{array}$ & $\begin{array}{l}14.82 \\
14.78 \\
14.74 \\
14.70 \\
14.66 \\
14.63\end{array}$ & $\begin{array}{l}3.0 \\
3.1 \\
3.3 \\
3.5 \\
3.6 \\
3.8\end{array}$ & $\begin{array}{l}09 E-15 \\
13 E-15 \\
32 E-15 \\
58 E-15 \\
68 E-15 \\
84 E-15\end{array}$ & $\begin{array}{l}-25.18 \\
-25.14 \\
-25.09 \\
-25.02 \\
-24.97 \\
-24.91\end{array}$ & $\begin{array}{l}0.02 \\
0.02 \\
0.02 \\
0.02 \\
0.02 \\
0.02\end{array}$ \\
\hline $\begin{array}{l}\text { Webb, Pollock, Pica, } \\
\text { Smith, and Leacock } \\
\text { Univ. Florida }\end{array}$ & $\begin{array}{l}6 \\
7\end{array}$ & $\begin{array}{ll}\operatorname{Dec} & 83 \\
\operatorname{Dec} & 83\end{array}$ & $\begin{array}{l}4400 \\
3600 \\
4400 \\
5500 \\
3600 \\
4400 \\
5500\end{array}$ & $\begin{array}{l}14.83 \\
14.92 \\
14.83 \\
14.74 \\
14.92 \\
14.83 \\
14.74\end{array}$ & & $\begin{array}{l}16.05^{9} \\
16.01 \\
15.92 \\
14.92 \\
16.00 \\
16.01 \\
14.91\end{array}$ & $\begin{array}{l}-25.26 \\
-25.53 \\
-25.21 \\
-25.02 \\
-25.52 \\
-25.24 \\
-25.02\end{array}$ & $\begin{array}{l}0.05 \\
0.06 \\
0.04 \\
0.05 \\
0.04 \\
0.04 \\
0.03\end{array}$ \\
\hline $\begin{array}{l}\text { Wisniewski } \\
\text { Steward Obs. }\end{array}$ & 16 & $\operatorname{Dec} 83$ & $\begin{array}{l}3600 \\
4400 \\
5500 \\
7000 \\
9000\end{array}$ & $\begin{array}{l}14.92 \\
14.83 \\
14.74 \\
14.63 \\
14.52\end{array}$ & & $\begin{array}{l}16.19 \\
16.26 \\
15.21 \\
14.34 \\
13.35\end{array}$ & $\begin{array}{l}-25.60 \\
-25.34 \\
-25.14 \\
-25.01 \\
-24.80\end{array}$ & $\begin{array}{l}0.01 \\
0.01 \\
0.01 \\
0.01 \\
0.01\end{array}$ \\
\hline
\end{tabular}


TABLE 1-Continued

\begin{tabular}{|c|c|c|c|c|c|c|c|}
\hline Name & & Date & Region & $\log \nu$ & Flux & $\log F_{\nu}$ & $\log \sigma$ \\
\hline $\begin{array}{l}\text { Neugebauer, Elias, } \\
\text { Soifer, and Matthews } \\
\text { Palomar Obs. }\end{array}$ & 19 & Nov 83 & $\begin{array}{r}1.25^{6} \\
1.65 \\
2.2 \\
3.7 \\
10.1\end{array}$ & $\begin{array}{l}14.37 \\
14.26 \\
14.13 \\
13.91 \\
13.47\end{array}$ & $\begin{array}{c}15.0^{5} \\
21.5 \\
30.1 \\
44.1 \\
111.0\end{array}$ & $\begin{array}{l}-24.73 \\
-24.61 \\
-24.49 \\
-24.35 \\
-23.94\end{array}$ & $\begin{array}{l}0.03 \\
0.03 \\
0.03 \\
0.03 \\
0.06\end{array}$ \\
\hline $\begin{array}{l}\text { Roellig } \\
\text { NASA, Palomar Obs. }\end{array}$ & 20 & Jan 84 & $\begin{array}{r}1.25 \\
1.65 \\
2.2 \\
3.7 \\
1000\end{array}$ & $\begin{array}{l}14.37 \\
14.26 \\
14.13 \\
13.91 \\
11.48\end{array}$ & $\begin{array}{r}15.8 \\
23.3 \\
31.9 \\
47.1 \\
1300.0\end{array}$ & $\begin{array}{l}-24.71 \\
-24.57 \\
-24.47 \\
-24.32 \\
-22.19\end{array}$ & $\begin{array}{l}0.02 \\
0.02 \\
0.02 \\
0.02 \\
0.48\end{array}$ \\
\hline Harvey et al. 1984 & 29 & Oct 83 & $\begin{array}{r}50 \\
100\end{array}$ & $\begin{array}{l}12.78 \\
12.48\end{array}$ & $\begin{array}{l}<180 \\
<400\end{array}$ & $\begin{array}{l}<-23.03 \\
<-22.87\end{array}$ & $\begin{array}{r}\text { upper } \\
\text { limits }\end{array}$ \\
\hline $\begin{array}{l}\text { Balonek, Dent, and } \\
\text { Kinsel }\end{array}$ & 19 & Jan 84 & $89.6^{7}$ & 10.95 & $2.50^{8}$ & -22.60 & 0.02 \\
\hline $\begin{array}{l}\text { Aller, Aller, } \\
\text { and Hodge } \\
\text { Univ. Mich. }\end{array}$ & $\begin{array}{r}3 \\
5 \\
13\end{array}$ & $\begin{array}{ll}\text { Dec } & 83 \\
\text { Dec } & 83 \\
\text { Dec } & 83\end{array}$ & $\begin{array}{r}14.50 \\
8.00 \\
4.80\end{array}$ & $\begin{array}{r}10.16 \\
9.90 \\
9.68\end{array}$ & $\begin{array}{l}3.040 \\
3.540 \\
3.520\end{array}$ & $\begin{array}{l}-22.517 \\
-22.451 \\
-22.453\end{array}$ & $\begin{array}{l}0.006 \\
0.011 \\
0.006\end{array}$ \\
\hline $\begin{array}{l}\text { Bregman, Glassgold, } \\
\text { and Huggins } \\
\text { NYU and NRAO }\end{array}$ & 30 & May 84 & $\begin{array}{l}2250^{3} \\
2450 \\
2550 \\
2650 \\
2750 \\
2850 \\
2950 \\
3050\end{array}$ & $\begin{array}{l}15.125 \\
15.088 \\
15.071 \\
15.054 \\
15.038 \\
15.022 \\
15.007 \\
14.993\end{array}$ & $\begin{array}{l}1.23 \mathrm{E}-15^{4} \\
9.02 \mathrm{E}-16 \\
1.02 \mathrm{E}-15 \\
7.73 \mathrm{E}-16 \\
9.01 \mathrm{E}-16 \\
1.19 \mathrm{E}-15 \\
1.17 \mathrm{E}-15 \\
9.81 \mathrm{E}-16\end{array}$ & $\begin{array}{l}-26.52 \\
-25.79 \\
-25.79 \\
-25.94 \\
-25.88 \\
-25.76 \\
-25.76 \\
-25.83\end{array}$ & $\begin{array}{l}0.18 \\
0.13 \\
0.05 \\
0.05 \\
0.04 \\
0.04 \\
0.04 \\
0.05\end{array}$ \\
\hline $\begin{array}{l}\text { Miller and Stephens } \\
\text { Lick Obs. }\end{array}$ & 31 & May 84 & $\begin{array}{l}4500 \\
5000 \\
5500 \\
6000 \\
6500 \\
7000\end{array}$ & $\begin{array}{l}14.82 \\
14.78 \\
14.74 \\
14.70 \\
14.66 \\
14.63\end{array}$ & $\begin{array}{l}2.65 E-15 \\
3.18 E-15 \\
3.48 E-15 \\
3.71 E-15 \\
3.92 E-15 \\
4.11 E-15\end{array}$ & $\begin{array}{l}-25.25 \\
-25.14 \\
-25.06 \\
-25.00 \\
-24.94 \\
-24.88\end{array}$ & $\begin{array}{l}0.02 \\
0.02 \\
0.02 \\
0.02 \\
0.02 \\
0.02\end{array}$ \\
\hline $\begin{array}{l}\text { Neugebauer, Elias, } \\
\text { Soifer, and Matthews } \\
\text { Palomar Obs. }\end{array}$ & 8 & Jun 84 & $\begin{array}{l}1.25^{6} \\
1.65 \\
2.2 \\
3.7\end{array}$ & $\begin{array}{l}14.37 \\
14.26 \\
14.13 \\
13.91\end{array}$ & $\begin{array}{l}21.5^{5} \\
30.2 \\
40.4 \\
53.0\end{array}$ & $\begin{array}{l}-24.58 \\
-24.46 \\
-24.36 \\
-24.27\end{array}$ & $\begin{array}{l}0.03 \\
0.03 \\
0.03 \\
0.03\end{array}$ \\
\hline $\begin{array}{l}\text { Dent, Kinsel, and } \\
\text { Balonek } \\
\text { Univ. Mass. }\end{array}$ & $\begin{array}{l}29 \\
12\end{array}$ & $\begin{array}{ll}\text { Apr } & 84 \\
\text { Jul } & 84\end{array}$ & $\begin{array}{l}89.60^{7} \\
89.60\end{array}$ & $\begin{array}{l}10.95 \\
10.95\end{array}$ & $\begin{array}{l}2.20^{8} \\
2.07\end{array}$ & $\begin{array}{l}-22.66 \\
-22.68\end{array}$ & $\begin{array}{l}0.03 \\
0.05\end{array}$ \\
\hline $\begin{array}{l}\text { Aller, Aller } \\
\text { Univ. Mich. }\end{array}$ & $\begin{array}{r}2 \\
4 \\
10\end{array}$ & $\begin{array}{l}\text { Jun } 84 \\
\text { Jun } 84 \\
\text { Jun } 84\end{array}$ & $\begin{array}{r}14.50 \\
8.00 \\
4.80\end{array}$ & $\begin{array}{r}10.16 \\
9.90 \\
9.68\end{array}$ & $\begin{array}{l}2.637 \\
3.036 \\
2.669\end{array}$ & $\begin{array}{l}-22.579 \\
-22.518 \\
-22.574\end{array}$ & $\begin{array}{l}0.004 \\
0.006 \\
0.016\end{array}$ \\
\hline
\end{tabular}

\footnotetext{
${ }^{1}$ Corrected for $E(B-V)=0.31$ or $\log N_{\mathrm{H}}=22.1$.

2 In ergs $\mathrm{cm}^{-2} \mathrm{~s}^{-1} \mathrm{~Hz}^{-1}$.

${ }^{3}$ In angstroms.

${ }^{4}$ In ergs cm ${ }^{-2} \mathrm{~s}^{-1} \mathrm{~A}^{-1}$

${ }^{5}$ Flux density in $\mathrm{mJy}$.

${ }^{6}$ Wavelength in $\mu \mathrm{m}$.

${ }^{7}$ Frequency in $\mathrm{GHz}$.

${ }^{8}$ Flux density in Jy.

${ }^{9}$ Magnitudes.
} 
TABLE 2

The Radio-Ultraviolet ContinuUm

\begin{tabular}{ccc}
\hline \hline Date & $\begin{array}{c}\text { Integrated Flux } \\
\left(10^{-10} \text { ergs cm }^{-2} \mathrm{~s}^{-1}\right)\end{array}$ & $\begin{array}{c}\text { Luminosity }\left(H_{\mathrm{o}}=75\right) \\
\left(10^{45} \mathrm{ergs} \mathrm{s}^{-1}\right)\end{array}$ \\
\hline 1980 Jun $\ldots \ldots \ldots \ldots$ & 4.5 & 4.2 \\
1983 Jun $\ldots \ldots \ldots \ldots$ & 2.2 & 2.1 \\
1983 Dec $\ldots \ldots \ldots$. & 2.1 & 2.0 \\
1984 May $\ldots \ldots \ldots$. & 2.5 & 2.5 \\
\hline
\end{tabular}

and IPC data is $\alpha=0.68 \pm 0.18$ (between energies $5.6 \mathrm{keV}$ and $1.0 \mathrm{keV})$. There is no evidence for brightness variation during the observing period, and a $1 \sigma$ limit of $30 \%$ can be set on minute-to-minute variations. Fourier analysis suggests that there may be periodic variations in the data of 53.4 and $9.65 \mathrm{~s}$ (at the $95 \%$ level), although more data are needed to produce a secure result.

1983 June.-Monitoring data show evidence for a minor radio outburst with a peak near 1983 June, in contrast to the infrared and optical observations, which show low values at this time (Fig. 1). IRAS data were obtained during a period of a few months that encompass 1983 June (Impey and Neugebauer 1988); the flux determination at $100 \mu \mathrm{m}$ is confused by IR cirrus and is not included. No variation was measured in any of the IRAS bands. The NRAO $12 \mathrm{~m}$ telescope had been

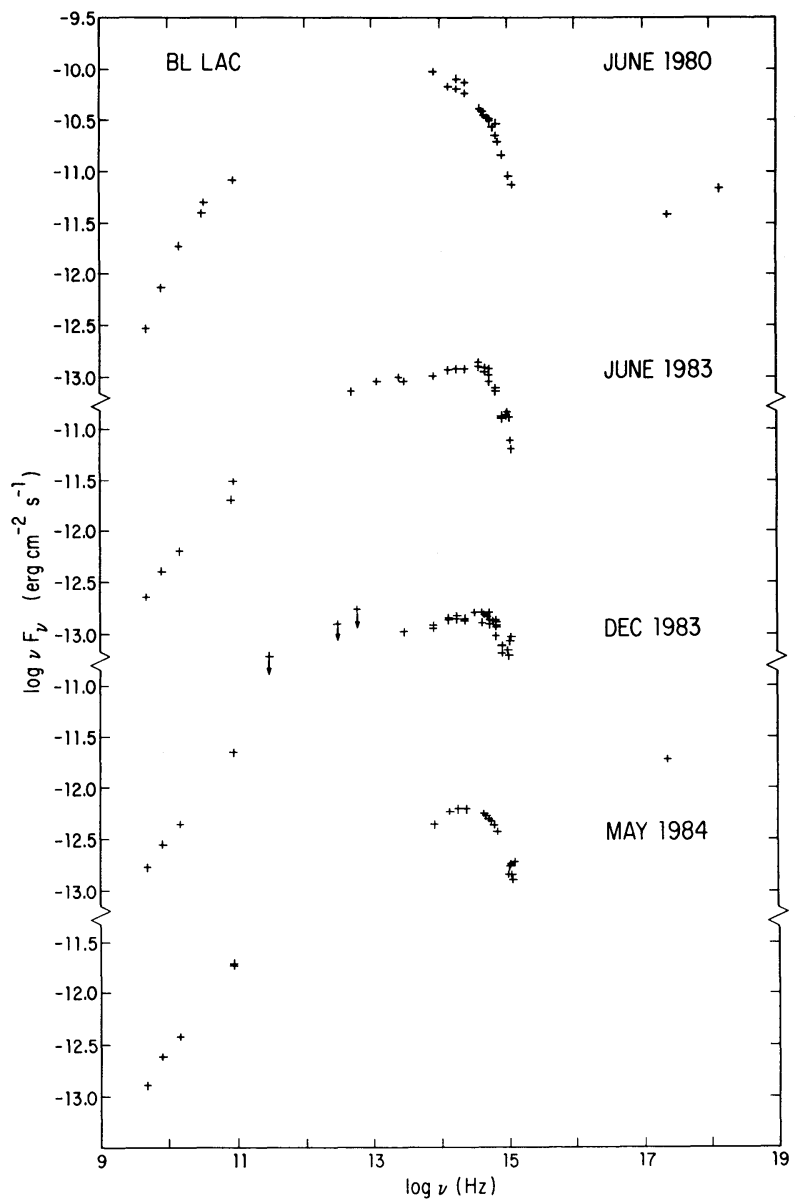

FIG. 5.- The multifrequency spectra of BL Lac on four separate occasions are plotted in power per logarithmic bandwidth vs. frequency. X-ray measurements were taken in 1980 June and 1983 December.

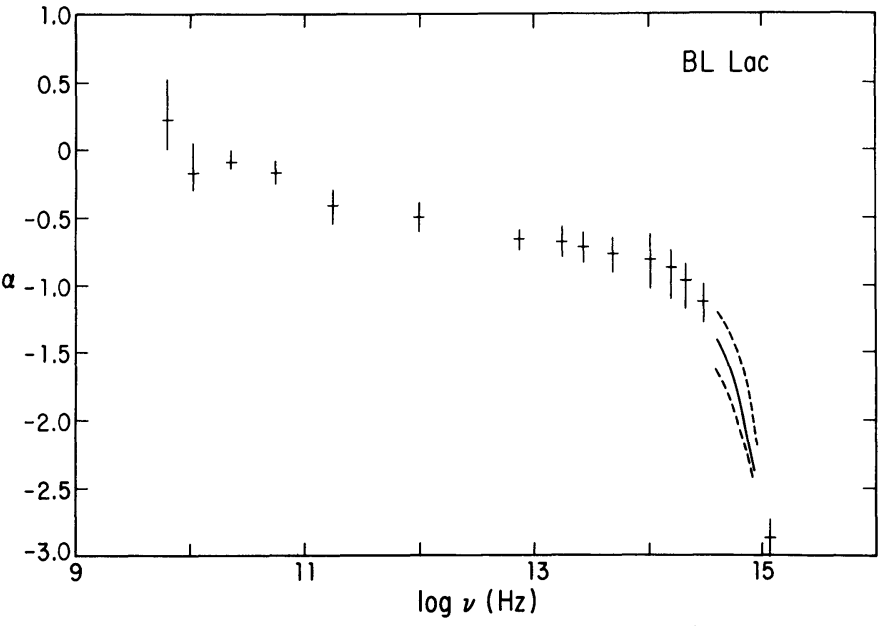

Fig. 6.-The average slope for the four multifrequency spectra. The vertical bars indicate the $1 \sigma$ range of the slopes and not the error in determining an individual slope in a multifrequency spectrum.

resurfaced shortly before the $90 \mathrm{GHz}$ observations, and pointing uncertainties probably led to the discrepancy between the two observations.

The spectral slope changes from a value of about $\alpha=-0.3$ in the radio-mm region to a value of about -0.8 in the infrared-optical region. The data suggest that this change occurs near $10^{12} \mathrm{~Hz}$, and this may denote the location where the synchrotron source changes from opaque to transparent.

1983 December.-The monitoring observations show a steady decrease in the radio flux density from mid-1983 at the same time that there is a slow increase in the mean opticalinfrared brightness. 1983 December is the only data in addition to 1980 June when simultaneous X-ray data were obtained. The EXOSAT observations were processed using the spectral index and absorption column deduced from the Einstein Observatory IPC observations. The value of the flux density, which depends upon the assumed spectral parameters, may be uncertain by $50 \%$ or more. However, when identical spectral parameters are used for the reduction of the Einstein Observatory and EXOSAT measurements, the flux density obtained during 1983 December is always fainter.

Like the 1980 June spectrum, an extension of the opticalultraviolet continuum into the $\mathrm{X}$-ray region falls far below the $\mathrm{X}$-ray emission. Relative to the 1980 June data, flux decreases are evident in the X-ray, infrared, millimeter, and radio data, while flux increases occur in the optical and ultraviolet regions (Fig. 7). This suggests that the $X$-ray emission is likely to be related to the infrared-radio emission rather than to the opticalultraviolet emission.

The radio continuum is characterized by a slope of $\alpha=-0.1$, which steepens to $\alpha=-0.5$ in the infrared. This change in slope occurs in the $10^{11}-10^{12} \mathrm{~Hz}$ region and may be the result of increasing transparency.

1984 May.-The trend of decreasing mean radio flux density and increasing mean optical-infrared brightness continues from mid-1983 to mid-1984 (Fig. 1). In this spectrum, the peak in the power per logarithmic bandwidth is extremely well defined (near $\log v=14.3-14.4$ ), and the optical-ultraviolet steepening is quite sharp. Like the 1983 June and 1983 December spectra, this spectrum shows a radio spectrum with slope $\alpha>-0.5$ that steepens in the region $\log v=11-12$. 


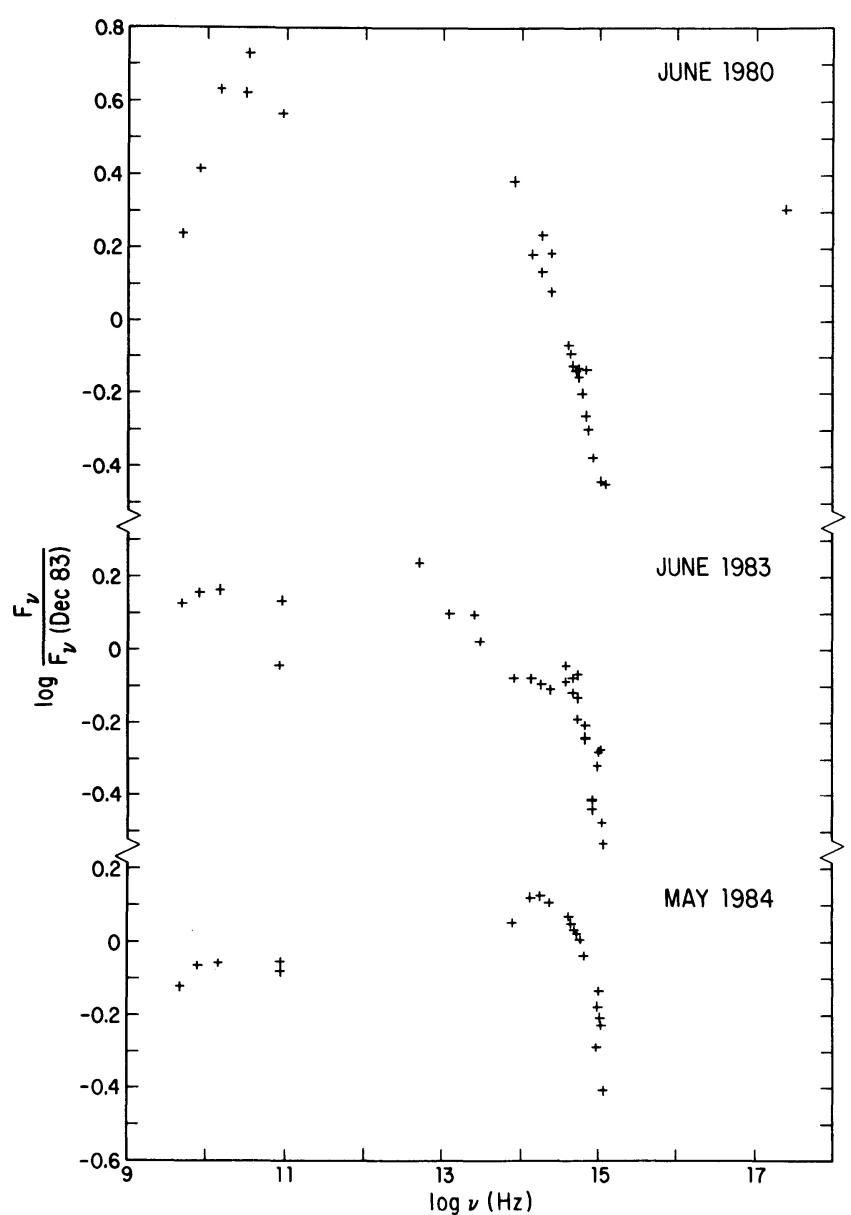

Fig. 7.- The multifrequency spectra are plotted relative to the 1983 December spectrum in order to reveal spectral changes. In 1980 June, the $\mathrm{X}$-ray, infrared, and radio emission were brighter while the optical and ultraviolet continuum was fainter.

\section{c) Differences Between Spectra}

To see detailed changes in spectra more clearly, we divided the spectra by the spectrum of 1983 December. For the 1983 December spectrum, the exact values of the radio, millimeter and X-ray region were used, and a smooth curve was fit through the infrared-ultraviolet region. The ratios of the fluxes are shown in Figure 7.

Unlike some BL Lac objects and violently variable quasars, whose spectral shapes show little time variation (e.g., Bregman et al. 1986, 1988), there are clear changes in the spectrum of BL Lac. Between 1983 June and 1984 May, the fractional brightening in the ultraviolet region is greater than in the optical region. Because of the rapid decrease in the optical-ultraviolet spectrum, a shift in the frequency of spectral turnover could account for the dramatic ultraviolet variations, which, however, contain little power. The decrease in the flux density of the radio-mm continuum between 1983 June and 1984 May reflects the decay of the outburst that peaked near mid-1983. The comparison of the 1983 December with the 1980 June spectrum indicates that the variation of the X-ray emission occurs in the same sense as the radio-infrared variations, but not as the optical-ultraviolet variations. d) The Peak of the Power Distribution

An extensive set of multicolor infrared measurements near the peak of the power per logarithmic bandwidth was obtained at the Palomar Observatory. On 19 occasions, observations were made on the same night in five filter bands: $1.25,1.65,2.2$, 3.7 , and $10.1 \mu \mathrm{m}$. In order to show the change in spectral shape, we scaled each spectrum in flux density so that they all have the same $1.25-10.1 \mu \mathrm{m}$ integrated power. The uncertainty in the data points of a single spectrum is typically $\log v F_{v}=0.03$, which is comparable to or smaller than the characteristic variation in the spectrum (i.e., the vertical bars in Fig. 8). In the majority of spectra, the peak in the power per logarithmic bandwidth is remarkably well defined and occurs either between 2.2 and $1.65 \mu \mathrm{m}$. In about one-quarter of the cases, the power per logarithmic bandwidth is evenly distributed from $1.65-10.1 \mu \mathrm{m}$. The mean $2.2-10.1 \mu \mathrm{m}$ slope is $\langle\alpha\rangle=-0.85$, while in the 1.25-2.2 $\mu \mathrm{m}$ range, $\langle\alpha\rangle=-1.19$, which indicates a steepening of $\Delta \alpha=-0.34$ over a frequency range of $\Delta \log$ $v=0.45$. This well-measured and rapid steepening should serve as a strong constraint in the development of successful radiation models.

\section{DISCUSSION}

\section{a) Sharp Spectral Cutoffs}

The remarkable cutoff in the continuum of BL Lac in the infrared-ultraviolet region is similar in shape to that seen in quasars with an unusually large near-infrared to optical brightness ratio (red quasars; Bregman et al. 1981; Beichman et al. $1981 a, b$; Rieke, Lebofsky, and Wisniewski 1982; Rieke, Lebofsky, and Kinman 1979). However, in red quasars, several of which are blazars, the cutoff occurs in the $1-10 \mu \mathrm{m}$ region rather than at $0.1-1 \mu \mathrm{m}$ (Fig. 9). X-ray data suggest there may exist a similar cutoff at yet higher frequencies for certain X-ray bright BL Lac objects. For example, Mrk 421 (Makino et al. 1987) has an IR-optical-ultraviolet spectrum that extends smoothly into the X-ray region, where the spectrum steepens (Ohashi 1988), implying a rapid cutoff to the emission. Thus, a continuum cutoff may be a common feature that occurs over a range of frequencies.

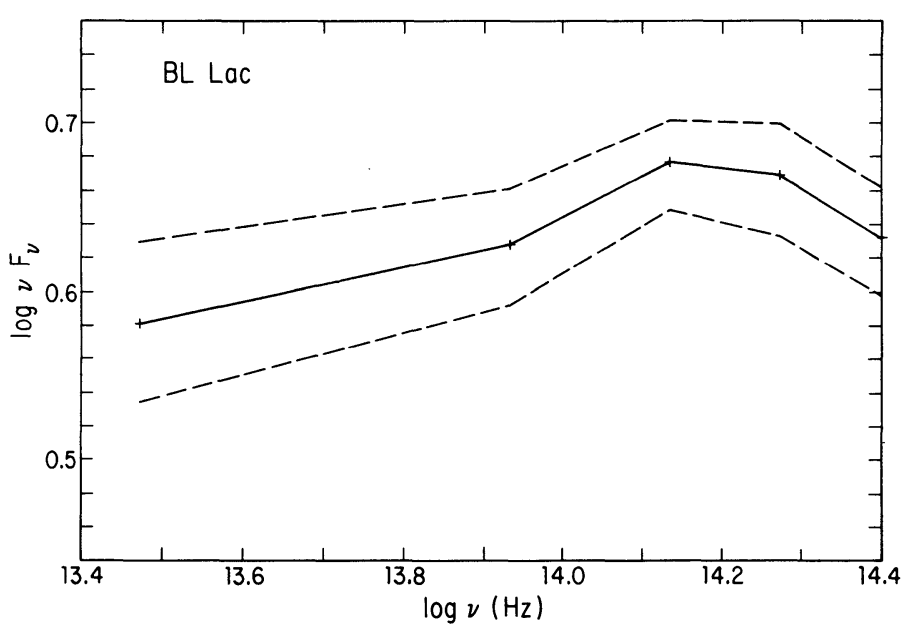

FIG. 8.- The mean infrared spectrum of BL Lac, which was obtained by averaging 19 spectra that were normalized to the same integrated flux. Twothirds of the spectra are contained within the region defined by the dashed lines. The normalization of the vertical scale is arbitrary. 


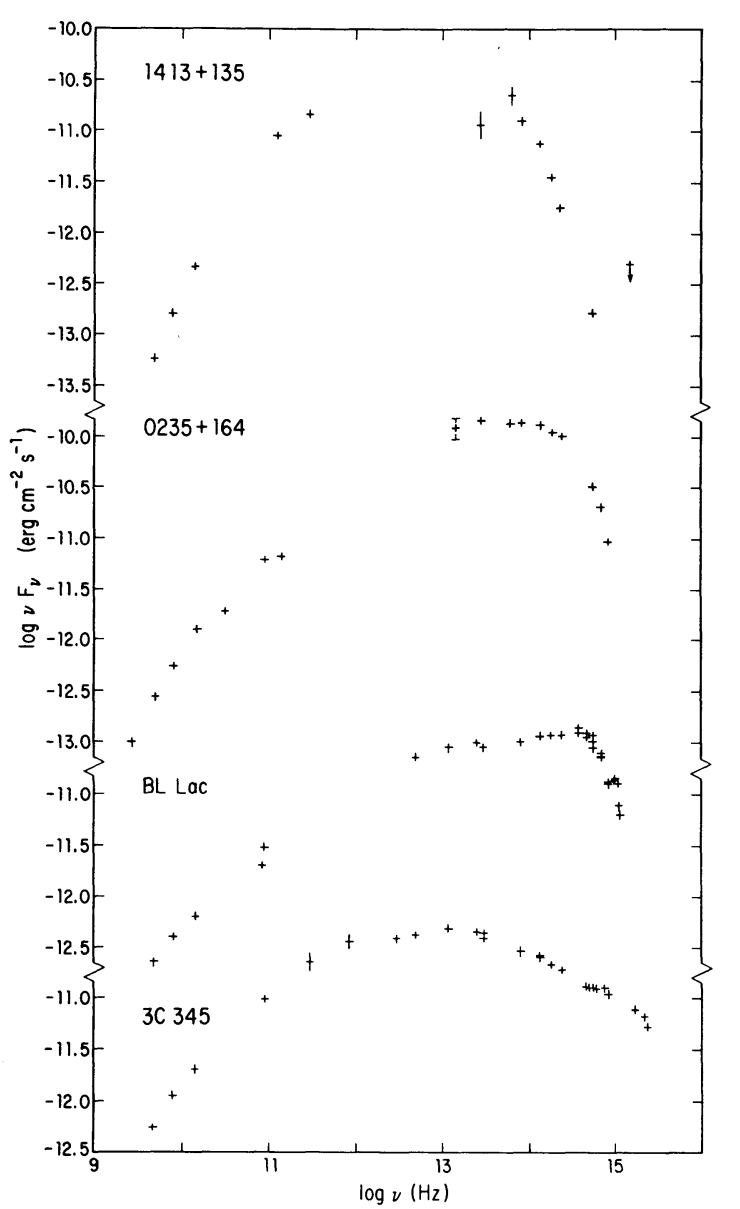

Fig. 9.-The multifrequency spectrum of BL Lac is compared to that of three blazars: the red quasar $1413+135$, the BL Lac object AO $0235+164$, and the violently variable quasar $3 C 345$. The sharp infrared-optical turnover occurs at progressively higher frequencies in the sequence proceeding from $1413+135$ to AO $0235+164$ to BL Lac. No such turnover is observed in $3 \mathrm{C} 345$.

These spectral cutoffs probably reflect a limit in the energy to which electrons are easily accelerated before synchrotron losses become important. To explain this feature, models have been developed in which electrons are accelerated near a shock by first-order Fermi acceleration (e.g., Blandford and Eichler 1987). When synchrotron losses are included, the electrons reach a limiting energy when the acceleration time scale exceeds the synchrotron time scale (Webb, Drury, and Biermann 1984; Bregman 1985; Heavens and Meisenheimer 1987; Biermann and Strittmatter 1987; Fritz 1989). These processes produce a sharp cutoff in the synchrotron continuum, and there has been some success in fitting these models to the data (Fritz 1988).

\section{b) Test of Radiation Models}

An important application of the observations is to test radiation models of the emitting region. The synchrotron-selfCompton model makes two simple predictions in the homogeneous case (e.g., Jones, O'Dell, and Stein 1974) and in some nonhomogeneous cases (e.g., Marscher 1977; Ghisellini, Maraschi, and Treves 1985): (1) the continuum of the seed photons and of the Compton emission should be similar, and (2) the seed photons should vary in concert with the Compton emission. For BL Lac, we examine whether the X-ray emission is produced by the Compton process. The 1980 June spectrum indicates that the $\mathrm{X}$-ray slope of $-0.68 \pm 0.18$ is the same as that in the $10^{11}-10^{14} \mathrm{~Hz}$ region, which we identify as the seed photon region. The variation in the spectrum between 1980 June and 1983 December shows that the X-ray emission decreased as did the emission in the $10^{9.5}-10^{14.4} \mathrm{~Hz}$ region. The optical and ultraviolet continuum, which are not identified as the seed photons, changed in the opposite sense to that of the X-ray emission. These observations qualitatively support the synchrotron-self-Compton model, and additional multifrequency spectra with accurate $\mathrm{X}$-ray continua are being obtained to investigate this issue more deeply. We note that in a competing model for the production of the X-ray emission, the pair cascade model (e.g., Fabian 1988), interactions between the $\gamma$-ray photons and the optical-ultraviolet photons lead to the X-ray emission. In this model, one expects the X-ray emission to be positively correlated with the optical-ultraviolet emission, the opposite of what we observe.

The physical properties of the emitting region can be estimated by fitting the synchrotron-self-Compton model to the data. An important parameter for the model is the frequency at which opacity effects become important $\left(v_{m}\right)$. The presence of a time delay in the variability between $90 \mathrm{GHz}$ and $15 \mathrm{GHz}$ suggests that the source is not entirely transparent until frequencies greater than $10^{11} \mathrm{~Hz}$ are reached. The data also indicate that a change in slope occurs in the $100-1000 \mathrm{GHz}$ range, so we have fit homogeneous models under the assumption that opacity effects first become significant in this spectral range.

A time scale of variability that reflects the size of the emitting region is also needed for the model in order to constrain the Doppler boosting parameter. The turnover in the power spectrum of the optical variability suggests that the size of the entire optical emitting region is about a light-day (Moore, Schmidt, and West 1987). In the radio region, outbursts can develop on a time scale of weeks. In choosing the variability time scale for the $100-1000 \mathrm{GHz}$ region, we have adopted values of half a week and of 1 day.

The models are fit to the two spectra with X-ray measurements, which is essential for constraining the Compton scattering contribution, and the results are presented in Table 3 . The best-constrained parameter is the size of the emitting region, which falls in the range $0.003-0.02$ pc. Every model indicates that modest relativistic boosting occurs, with $\delta=2-16$, where $\delta=[\gamma(1-\beta \cos \theta)]^{-1}$. For the least Doppler boosting (model 1983 December $C$ ), the bulk motion of the emitting plasma must be within $30^{\circ}$ of our line of sight, while for the largest value of $\delta$ (model 1980 June $D$ ), the motion must be within 3.6 of our line of sight. The selection of a preferred model is aided by Hughes, Aller, and Aller (1989b), who fit a propagating shock model to an independent data set, the

TABLE 3

SynChrotron SELF- Compton Models For BL LAC

\begin{tabular}{|c|c|c|c|c|c|c|c|}
\hline Model & $\begin{array}{c}v_{m} \\
(\mathrm{GHz})\end{array}$ & $\underset{(\mathrm{Jy})}{F_{v}\left(v_{m}\right)}$ & $\begin{array}{c}t_{\text {var }} \\
\text { (weeks) }\end{array}$ & $\begin{array}{c}B \\
(G)\end{array}$ & $\underset{(p c)}{r}$ & $\begin{array}{c}n \\
\left(\mathrm{~cm}^{-3}\right)\end{array}$ & $\delta$ \\
\hline 1980 Jun A .... & 100. & 8.71 & 0.5 & 0.088 & 0.021 & 68 & 14.8 \\
\hline 1980 Jun B $\ldots$. & 316. & 6.00 & 0.5 & 1.61 & 0.010 & 110 & 7.2 \\
\hline 1980 Jun C $\ldots$. & 1000. & 3.50 & 0.5 & 30. & 0.0046 & 240 & 3.3 \\
\hline 1980 Jun D .... & 316. & 6.00 & 0.14 & 0.51 & 0.0062 & 190 & 15.6 \\
\hline $1983 \operatorname{Dec} A \ldots$ & 100. & 2.30 & 0.5 & 0.13 & 0.013 & 200 & 9.4 \\
\hline 1983 Dec B .... & 316. & 1.26 & 0.5 & 2.4 & 0.0058 & 460 & 4.2 \\
\hline 1983 Dec C .... & 1000 . & 0.68 & 0.5 & 44. & 0.0026 & 1080 & 1.9 \\
\hline 1983 Dec D .... & 316. & 1.26 & 0.14 & 0.75 & 0.0036 & 740 & 9.0 \\
\hline
\end{tabular}


VLBI, and the radio monitoring observations. Their best model has $\delta \approx 1$ and $\theta \simeq 38^{\circ}$. A few of our models have $\delta \lesssim 4$, but none have $\delta \approx 1$. This difference with the propagating shock model could easily be due to the simplicity of our model or a slight underestimation of $v_{m}$. Our models with the smallest values of $\delta$ are 1980 June C, 1983 December B, and 1983 December C (Table 3), which suggest that the plasma emitting at frequency $v_{m}$ has a magnetic field strength of 2-40 G. The inability to specify $v_{m}$ accurately prevents a comparison of the physical parameters for the two separate dates. The energy density associated with the magnetic field is considerably greater than that associated with the particles, which implies that the rapid radiative losses are balanced by particle reacceleration.

Nonhomogeneous synchrotron-Compton models (e.g., Ghisellini, Maraschi, and Treves 1985) suggest that the plasma emitting at higher frequencies, such as the optical emission, comes from a region smaller by an order of magnitude or more, with a correspondingly more intense magnetic field strength and greater particle density.

\section{c) Flux Density Correlations}

The monitoring data ( $\S$ II) yield information about the structure of the emitting plasma in BL Lac. It is not surprising that the variations in the infrared-optical emission show no time delay, which is expected if the emission is produced cospatially by the synchrotron process in a transparent region. With regard to the radio emission, the time delay between variations in neighboring wavebands is short, suggesting that optical depth effects are small. If the time delays measured between 4.8 $\mathrm{GHz}$ and $89.6 \mathrm{GHz}$ can be extrapolated to the infrared-optical region, we estimate that the infrared-optical flux variations should precede the radio variations by about 4 months. However, a much longer time delay is determined from the correlation analysis, 1.5-4 yr. Furthermore, the structure function analysis shows that the behavior of the flux density variations is quantitatively different between the infrared-optical and the radio bands. Both of these results suggest that the radio emission region is not simply the optically emitting plasma that eventually becomes transparent.

The observations might be understood in terms of a model in which disturbances (e.g., input of fresh plasma) are created by outbursts associated with optical emission. The disturbance propagates outward, producing little radiation until it creates a shock in more distant plasma, giving rise to the radio emission. The similarity between the observed time delay of a few years and the light crossing time of the measured VLBI size support this picture. The light crossing time of the radio region is longer than the time separating rapid disturbances in the optical region (that produce optical flickering). This lessens the amplitude of short time scale radio variability, causing the radio structure function to be steeper than its optical counterpart, as is observed.
It may be possible to use the optical monitoring data to plan VLBI observing strategies. The correlation between the optical and radio behavior and the correlation between radio outbursts and superluminal components suggests that superluminal behavior can be linked to optical outbursts. This result was also found for 3C 345 (Bregman et al. 1986).

\section{d) Final Comments}

The data show that the emitting region is inhomogeneous, with a small inner region of high density and magnetic field (the optically emitting region) that eventually becomes a large, partially opaque radio emitting region with a low density and magnetic field. The $\mathrm{X}$-ray emission appears to be produced by Compton scattering of the infrared-submillimeter photons. The synchrotron-self-Compton model was fit to the multifrequency spectra to determine the plasma parameters near $v_{m} \sim 10^{11.5} \mathrm{~Hz}$. Hughes, Aller, and Aller $(1989 b)$ fit a propagating shock model to the radio variations at $\mathrm{cm}$ wavelengths $\left(10^{10} \mathrm{~Hz}\right)$ to determine the physical conditions in this region. Because each of these approaches is limited in scope, we point out the need for a more general model that can explain the full assortment of observations presented here: the overall spectral shape as well as the time variability data (i.e., the structure function, the shape of outbursts, the frequency-dependent time delays).

One of the most important results of this work is that the two simple predictions of the synchrotron-self-Compton model are reproduced in the multifrequency spectra. Since the variability data supporting this conclusion rests on two such spectra (taken with two different instruments), there is concern that this was simply a chance coincidence. Consequently, we are obtaining additional multifrequency data which include $X$-ray data with greatly improved spectral information (from the GINGA observatory) and will report upon the results in a future work.

We would like to thank Rick Howard for using test time to make millimeter measurements of BL Lac and Anne Kinney for-her assistance with $I U E$ data reduction. IUE observing at NYU was supported by NASA grant NAG 5-73; J. N. B. would like to acknowledge support from grant NAG-5-1059; radio astronomy at the University of Michigan is supported by the NSF through grant AST-8501093 and AST-8815678; J. S. M. and S. S. wish to acknowledge Lick Observatory and the NSF for their support; W. A. D., and W. K. have been aided by the NSF and the University of Massachusetts; infrared astronomy at Caltech gratefully acknowledges continued support by the NSF; funding for IRAS observations and data reduction were provided by ESA, SERC, and NASA; W. Z. W. would like to thank Steward observatory for their support. The long-term University of Florida observations have been supported by a series of grants from the NSF; the current grant is AST-8516269.

\section{REFERENCES}

Aller, H. D., Aller, M. F., and Hughes, P. A. 1985, Ap. J., 298, 296. 1988, in The Impact of VLBI on Astrophysics and Geophysics, ed. M. J. Reid and J. M. Moran (Dordrecht: Reidel), p. 83.

Aller, H. D., Aller, M. F., Latimer, G. E., and Hodge, P. E. 1985, Ap. J. Suppl., 59, 513.

Baath, L. B., Elgered, G., Lundqvist, G., Graham, D., Weiler, K. W., Seielstad, G. A., Tallqvist, S., and Schilizzi, R. T. 1981, Astr. Ap., 96, 316.

Balonek, T. J. 1982, Ph.D. thesis, University of Massachusetts.

Beichman, C. A., Neugebauer, G., Soifer, B. T., Wootten, H. A., Roellig, T., and Harvey, P. M. 1981 a, Nature, 293, 711.
Beichman, C. A., Provdo, S. H., Neugebauer, G., Soifer, B. T., Matthews, K., and Wootten, H. A. 1981b, Ap. J., 247, 780.

Biermann, P. L., and Strittmatter, P. A. 1987, Ap. J., 322, 643.

Bjornsson, C.-I. 1986, in Continuum Emission in Active Galactic Nuclei, ed M. L. Sitko(Tucson: NOAO), p. 181.

Blandford, R. D., and Eicher, D. 1987, Phys. Rept., 154, 1.

Bregman, J. N. 1985, Ap. J., 288, 32.

Bregman, J. N., Lebofsky, M. J., Aller, M. F., Rieke, G. H., Aller, H. D., Hodge,

P. E., Glassgold, A. E., and Huggins, P. J. 1981, Nature, 293, 714.

Bregman, J. N., et al. 1982, Ap. J., 253, 19. 
1984, Ap. J., 276, 454.

1986, Ap.J., 301, 708

. 1988, Ap. J., 331, 746.

Brindle, C., et al. 1985, M.N.R.A.S. 214, 619.

Burstein, D., and Heiles, C. 1978, Ap. J., 225, 40.

I Du Puy, D., Schmitt, J. L., McClure, R., van den Bergh, S., and Racine, R. 1969, Ap. J.(Letters), 156, L35.

Epstein, E. E., Fogarty, W. G., Mottmann, J., and Schneider, E. 1982, A.J., 87, 449.

Fabian, A. C. 1988, in Supermassive Black Holes, ed. M. Kafatos (Cambridge: Cambridge University Press), p. 234.

Fielder, R. L., et al. 1987, Ap. J. Suppl., 65, 319.

Fritz, K.-D. 1988, Bull. AAS, 20, 1064. 1989, Astr. $A p$., in press.

Ghisellini, G., Maraschi, L., and Treves, A. 1985, Astr. Ap., 146, 204

Glassgold, A. E., et al. 1983, Ap. J., 274, 101.

Hagen-Thorn, V. A., Marchenko, S. G., and Yacovleva, V. A. 1985, Astrofizika, 22,5 .

Hagen-Thorn, V. A., and Yacovleva, V. A. 1987, in IAU Symposium 121, Observational Evidence of Activity in Galaxies, ed. E. Ye. Khachikian, G. Melnick, and K. Fricke (Dordrecht: Reidel), p. 325.

Heavens, A. F., and Meisenheimer, K. 1987, M.N.R.A.S., 225, 335

Hughes, P. A., Aller, H. D., and Aller, M. F. 1985, Ap. J., 298, 301

- 1988, in IAU Symposium 129, The Impact of VLBI on Astrophysics and Geophysics, ed. M. J. Reid and J. M. Moran (Dordrecht: Reidel), p. 81. .1989a, Ap.J., 341, 54

- 1989b, Ap.J., 341, 68

Impey, C. D., Brand, P. W. J. L., Wolstencroft, R. D., and Williams, P. M. 1984 M.N.R.A.S., 209, 245 .

Impey, C. D., and Neugebauer, G. 1988, A.J., 95, 309.

Johnston, K. J., et al. 1984, Ap. J. (Letters), 277, L31.

Jones, T. W., O'Dell, S. L., and Stein, W. A. 1974, Ap. J., 188, 353.

Kondo, Y., et al. 1981, Ap. J., 243, 690.

Landau, R., et al. 1986, Ap. J., 308, 78 .

Maraschi, L., Schwartz, D. A., Tanzi, E. G., and Treves, A. 1985, Ap. J., 294, 615

H. D. Aller, M. F. Aller, and P. A. Hughes: Department of Astronomy, University of Michigan, 953 Physics-Astronomy Building, Ann Arbor, MI 48109

T. J. BALONEK : Department of Physics and Astronomy, Colgate University, Hamilton, NY 11346

P. W. J. L. BRAND: Department of Astronomy, University of Edinburgh, Royal Observatory, Edinburgh EH9 3HJ, Scotland

J. N. BRegman: Department of Astronomy, University of Michigan, Dennison Building, Ann Arbor, MI 48109-1090

W. A. Dent and W. KInsel: Department of Physics and Astronomy, GR Tower B, University of Massachusetts, Amherst, MA 01003

J. H. Elias: Cerro Tololo Inter-American Observatory, P.O. Box 26732, Tucson, AZ 85726-6732

B. GARILli and D. MaCCAGNi: Istituto di Fisica Cosmica, CNR, via Bassini 15, I-20133 Milano, Italy

P. Giommi: EXOSAT Observatory, ESTEC, Space Science Department, 2200 AG Noordwijk, The Netherlands

A. E. Glassgold and P. J. Huggins: Physics Department, New York University, 4 Washington Place, New York, NY 10003

W. H.-M. Ku: Columbia Astrophysics Laboratory, Physics Department, Columbia University, New York, NY 10024

R. J. LeACOCK and A. G. SMITH: Department of Astronomy, University of Florida, Gainesville, FL 32611

K. Matthews, G. Neugebauer, and B. T. Soifer: Division of Physics, Mathematics and Astronomy, Caltech, Pasadena, CA 91125

J. S. Miller and S. STEPHENS: Lick Observatory, University of California, Santa Cruz, CA 95064

J. T. Pollock: Department of Physics and Astronomy, Appalachian State University, Boone, NC 28608

J. R. WeBB: Department of Physics and Astronomy, Stephen F. Austin State University, P.O. Box 13044, SFA Station, Nacogdoches, TX 75962-3044

P. M. Williams: Royal Observatory, Blackford Hill, Edinburgh EH9 3HJ, Scotland

W. Z. WISNIEWSKI: Steward Observatory, University of Arizona, Space Sciences Building, Tucson, AZ 85721 